\title{
Bioguided Fractionation and Purification of Natural Bioactives Obtained from Alpinia conchigera Water Extract with Melanin Inhibition Activity
}

\author{
Zanariah Binti Ujang $^{1 *}$, Thavamanithevi Subramaniam ${ }^{1}$, Mazita Md Diah ${ }^{1}$, Harmayumi Binti Wahid ${ }^{1}$, \\ Badariah Binti Abdullah', Ahmad Hazri Bin Abd Rashid², David Appleton ${ }^{3,4}$ \\ ${ }^{1}$ Natural Product and Cosmetics Program, SIRIM Bhd. No. 1, Persiaran Dato Menteri, Shah Alam, Malaysia; ${ }^{2}$ Industrial Biotechnol- \\ ogy Research Centre, SIRIM Bhd. No. 1, Persiaran Dato Menteri, Shah Alam, Malaysia; ${ }^{3}$ Department of Pharmacology, Faculty of \\ Medicine, University of Malaya, Kuala Lumpur, Malaysia; ${ }^{4}$ Sime Darby Technology Centre Sdn. Bhd., UPM-MTDC Technology \\ Centre III, Universiti Putra Malaysia, Serdang, Malaysia. \\ Email: 'zanariah@sirim.my, thava@sirim.my,mazita@sirim.my,hmayumi@sirim.my, bdariah@sirim.my, ahazri@sirim.my, \\ david.ross.appleton@simedarby.com
}

Received May $16^{\text {th }}, 2013$; revised June $12^{\text {th }}, 2013$; accepted June $20^{\text {th }}, 2013$

Copyright (c) 2013 Zanariah Binti Ujang et al. This is an open access article distributed under the Creative Commons Attribution License, which permits unrestricted use, distribution, and reproduction in any medium, provided the original work is properly cited.

\begin{abstract}
Crude extracts of Alpinia conchigera a species from the Malaysian Ginger (Zingiberaceae) family and its fractions obtained from various extraction methods were assayed for melanogenesis inhibition activity and cell viability. The crude extract obtained from the ethanolic extraction and the super critical fluid extraction did not exhibit significant melanin inhibition activity and was shown to be toxic to the melanocyte cells in comparison to the water extract. The crude aqueous extracts displayed melanin inhibition of $96.38 \pm 1.60 \%$ and cell viability $109.90 \pm 8.32 \%$ at a concentration of $500 \mu \mathrm{g} / \mathrm{mL}$. Bioassay guided fractionation was performed on the water extracts to isolate the active compounds. The actives were identified as trans-cinnamaldehyde and chavicol glucopyranoside with both compound showing potent anti-melanogenesis activity. At $4.9 \mu \mathrm{g} / \mathrm{ml}$, both trans-cinnamaldehyde and chavicol glucopyranoside gave $85 \%$ inhibition of melanin formation in vitro with $77 \%$ and $97 \%$ cell viability respectively. In comparison, kojic acid, a known skin lightening agent showed $90.0 \%$ inhibition at $100 \mu \mathrm{g} / \mathrm{mL}$. The bioactive composition comprising the extract, active fraction, purified compounds or mixture thereof of Alpinia conchigera may be used for cosmetic and pharmaceutical applications, particularly for the purposes of reducing skin pigmentation.
\end{abstract}

Keywords: Alpinia Conchigera; Preparatory HPLC Fractionation; Chavicol Glucopyranoside; Trans Cinnamaldehyde; Anti-Melanogenesis Activity

\section{Introduction}

The Zingiberaceae plant, Alpinia conchigera Griff is a herbaceous perennial, 2.5 feet tall, widely cultivated in China, India and Southeast Asian countries such as Thailand, Indonesia, and Malaysia. In Malaysia, it is known locally as "lengkuas ranting”, "lengkuas kecil”, "lengkuas padang", "lengkuas getting" or "chengkenam" [1,2].

It has been used as a condiment in the northern states of Peninsular Malaysia and occasionally in traditional medicine to treat fungal infections [3]. This plant has been well studied for its potential to treat human breast carcinoma cells [4], human T cell lymphoma [5] and in

"Corresponding author. the inhibition of tumor promoter-induced Epstein-Barr virus [6]. In this study, we have found that Alpinia conchigera water extracts possess and anti-melanogenesis activity, leading to its potential use as an active skin whitening cosmetic agent.

Skin-whitening agents have been widely used to lighten skin color or treat abnormal hyperpigmentation in skin. Various dermatological disorders, such as melasma, age and liver spots, and sites of actinic damage arise from the accumulation of an excessive level of epidermal pigmentation. The inadequacy of current therapies to treat these conditions as well as high cytotoxicity, mutagenicity, poor skin penetration and low stability of formulations have led scientists to seek new whitening agents that better meet the medical requirements of de- 
pigmenting agents.

Melanin is the major pigment in human skin and is secreted by melanocyte cells in the basal layer of the epidermis [7]. Under chronic sun exposure, melanin may be overproduced with melasma or other hyperpigmentation diseases [8]. Therefore, a number of depigmenting agents have been developed to treat cases of undesirable skin discoloration. Tyrosinase, a copper-containing monooxygenase is a key enzyme that catalyzes melanin synthesis in melanocytes [9]. It catalyzes two major reactions, including hydroxylation of tyrosine and oxidation of the o-diphenol product, l-dopa. Dopa oxidation produces a highly reactive intermediate that is further oxidized to form melanin by a free radical-coupling pathway. Melanin biosynthesis can be inhibited by avoiding ultraviolet (UV) light exposure, inhibition of melanocyte metabolism and proliferation, by inhibition of tyrosinase, or by removal of melanin by corneal ablation. Application of tyrosinase inhibitors is the least invasive procedure for maintaining skin pigmentation; hence such agents are included in most cosmetic formulations [10]. Common skin whitening agents include hydroquinone, kojic acid and ascorbic acid derivatives. Efficacy in treatment of hyperpigmentary disorders has been demonstrated, although with varying success [11]. Adverse reactions associated with the use of hydroquinone include irritant dermatitis, nail discoloration, post-inflammatory hyperpigmentation [12] and ochronosis [13].

The rhizome of Alpinia conchigera has been extensively used as a spice for flavoring food, as well as in Thai traditional medicine for the treatment of various diseases such as skin disease, venereal disease, and bronchitis, or as an appetizer, digestive stimulant, analgesic and anti-inflammatory treatment in Vietnam [14]. This plant has also been reported to have gastroprotective effects [15]. The reported chemical constituents isolated from Alpinia conchigera include chavicol, chavicol acetate, 1'-acetoxychavicol acetate, eugenol, terpenoids, $\beta$ bisabolene, 1,8 -cineole, $\beta$-caryophyllene and cardamomin [16-20]. However, the anti-melanogenesis activity of the water extract of this plant has not been reported to date. In this report, we have performed the extraction and fractionation of water extract of Alpinia conchigera and subjected the fractions to in vitro melanin inhibition assay in order to identify the bioactive compounds associated with the anti-melanogenesis effect.

\section{Materials and Method}

\subsection{Chemicals}

The chemicals L-ascorbic acid, 1, 1-diphenyl-2-picrylhydroxyl (DPPH), kojic acid, synthetic melanin, diphenyl tetrazolium bromide (MTT) and tricholoroacetic acid
(TCA) were purchased from Sigma Chemical Co (St Louis, MO. USA). B16-F1 (CRL-6323) melanoma cells, penicillin and streptomycin, cell culture medium, fetal calf serum (Gibro-BRL) and supplements were purchased from American Type Culture Collection. All solvents were obtained from Scharlau Chemicals (Germany).

\subsection{Collection of Alpinia conchigera}

Fresh rhizomes of Alpinia conchigera were collected from Temerloh, Pahang, a state in Peninsular Malaysia. The gingers were identified by a botanist from Forest Research Institute of Malaysia (FRIM).

\subsection{Raw Material/Rhizome}

The rhizomes of Alpinia conchigera were washed with tap water followed by distilled water and later air dried. The sliced rhizomes were further dried in oven at $40^{\circ} \mathrm{C}$ for $24 \mathrm{~h}$ then powdered using a mechanical miller.

\section{Extraction Methods}

\subsection{Aqueous Extraction}

Extracts were prepared by stirring the powdered rhizomes into a solution of water. The ratio of powdered rhizome to water was maintained at 1:20 (w/v). The extraction was performed at $40^{\circ} \mathrm{C}$ and left overnight under gentle agitation. The extract was later centrifuged, filtered and freeze dried. The freeze dried crude extracts were then used for fractionation and purification studies.

\subsection{Solvent Extraction}

Extraction was carried out using powdered rhizomes and ethanol at ratio 1:10 (w/v). The suspension was left to shake for 24 hours at room temperature on a rotary shaker. Upon completion, the suspension was filtered using Whatman 114 filter paper and its filtrate collected. The solvent filtrate was evaporated to dryness under vacuum.

\subsection{Supercritical Fluid Extraction (SFE)}

The ground rhizomes were placed in the extraction vessel and Supercritical Fluid Extraction (SFE) was performed using Thar SFE 500 instrument at 300 - 550 bar, temperature of $40^{\circ} \mathrm{C}-50^{\circ} \mathrm{C}$ for $3 \mathrm{~h}$ using $\mathrm{CO}_{2}$ at a flow rate of $30 \mathrm{~g} / \mathrm{min}$. The extract was collected from the collection vessel and the collection vessel was flushed with ethanol to collect the remaining extract.

\section{Fractionation of Extracts (LCMS)}

Fractionation was performed using Shimadzu Liquid Chromatography with Waters X-Bridge reverse phase C18 column $(2.5 \mu \mathrm{m}, 2.1 \times 50 \mathrm{~mm})$. Gradient solvent system using ACN: water was used from $10 \%$ to $100 \%$ 
for 7 minutes. $40 \mu \mathrm{g} / \mathrm{ml}$ of Zingiberaceae aqueous extract was fractionated during a complete gradient solvent system to 18 fractions which the fraction was in equivalent dose concentration by Gilson Fraction Collector in the microplate. $10 \%$ DMSO was used to dissolve the samples for assay (equivalent dose concentration). All fractions and the crude were then analysed for the inhibition of melanin synthesis in vitro.

\subsection{Preparative HPLC}

Freeze dried extract of the Alpinia conchigera (100 - 200 $\mathrm{mg}$ ) was dissolved in $2 \mathrm{~mL}$ water:methanol (1:1). The extract solution was then centrifuged, and the supernatant ( $2 \mathrm{~mL}$, equivalent to $\sim 150 \mathrm{mg}$ extract) was subjected to preparative scale HPLC in order to isolate the active components.

Isolation was performed using a Gilson Preparative HPLC equipped with a GX-281 liquid handler and 156 UV detector. The columns used were Waters Novapak 25 $\times 100 \mathrm{~mm}$ RPC18 cartridge and $10 \mathrm{~mm}$ guard in a PrepLC $25 \mathrm{~mm}$. Chromatographic separation was accomplished using a gradient of elution from $100 \%$ water $(0.1 \%$ formic acid) to $100 \%$ acetonitrile $(0.1 \%$ formic acid) over a duration of 50 min, with a flow rate of 12 $\mathrm{mL} / \mathrm{min}$. The detection wavelengths used were 210 and $350 \mathrm{~nm}$ with 80 fractions being collected at duration of $0.5 \mathrm{~min} /$ fraction. Fractions collected were evaporated to dryness under vacuum and tested for biological activity. The purified active compounds were analysed and structure elucidated using NMR and LCMS.

\section{Melanogenesis Inhibition}

To determine the effect of Alpinia conchigera extracts on melanogenesis and viability, B16 melanoma cells were cultured in the presence of the test substances. The B16F1 (ATCC CRL-6323, melanoma cell line was purchased from American Type Culture Collection) cells were seeded into 24 well plates at $1 \times 10^{5}$ cells $/ \mathrm{mL}$ and cultured until they reached $90 \%$ confluence. They were then treated with sample at various concentrations using kojic acid as a standard. The extracellular melanin content and cell viability were measured after an incubation period of $48 \mathrm{~h}$. Cells were harvested for melanin content and viability determination.

\subsection{Viability Assay (MTT)}

Viability of cultured cells was determined by reduction of MTT (Sigma) to formazan (Mosmann 1983). MTT agent $(5 \mathrm{mg} / \mathrm{mL})$ was added into each well and cells incubated for $3 \mathrm{~h}$ at $37^{\circ} \mathrm{C}$ in a humidified incubator containing $5 \% \mathrm{CO}_{2}$. Cells were then centrifuged and dis- solved with DMSO. Absorbance was measured using spectrophotometer at $590 / 630 \mathrm{~nm}$. $\mathrm{ZnSO}_{4}$ was used as the positive control. All assays were done in triplicate.

\subsection{Structure Elucidation of Active Compound}

NMR spectra were obtained using Jeol ECA (400 MHz) NMR spectrometer. The active and purified compounds (trans-cinnamaldehyde and chavicol glucopyroanoside) were characterized by ${ }^{1} \mathrm{H}$ and ${ }^{13} \mathrm{C}$ NMR.

\section{Results}

\subsection{Extraction Yield of Alpinia Crude Extract}

The finely ground rhizomes of Alpinia conchigera were subjected to different extraction methods. The extraction yield is as shown in Table $\mathbf{1}$.

\subsection{Bioassay Guided Fractionation LCMS}

A common approach for studying crude plant extract and it's fractions is by doing bioassay-guided fractionation. With this technique, fractions are screened in pursuit of those that contain biologically active compounds. The active fractions are then identified and further isolated and purified. The above technique has been applied to isolate and purify the anti-melanogenesis compounds in Alpinia conchigera water extract (ZAE) used in this study. The crude aqueous extract displayed dose dependent melanin inhibition activity and was non toxic to the melanocyte cells as shown in Figure 1. $\mathrm{ZnSO}_{4}$ was used as the positive control for the cytotoxicity effect on the melanocyte cells.

During the complete gradient solvent system run on LCMS, 18 fractions were collected in a microplate and the fractions were subjected to in vitro melanin inhibition assay to identify the potent fractions. Figure 2 showed the percentage of melanin inhibition and cell viability of fractions 1 to 18 .

From the chromatogram, it can be observed that Fractions F2, F3, F5 and F6 displayed good melanogenesis inhibition activity with 56.5, 69.0, 58.3 and 52.9\% inhibition respectively at equivalent dose concentration, compared to kojic acid, a commercial skin lightening

Table 1. Yield of Alpinia conchigera crude extract with different extraction methods.

\begin{tabular}{cc}
\hline Extraction method & Extraction yield (\%) \\
\hline Aqueous water extraction method & 2.15 \\
Extraction with ethanol & 10.76 \\
Supercritical fluid extraction method & 3.25 \\
\hline
\end{tabular}


agent. The fractions which gave melanogenesis inhibition of more than $50 \%$ and cell viability of more than $70 \%$ was considered for further fractionation scale up using Prep HPLC. The HPLC chromatogram of the Alpinia conchigera water extract at wavelength $190 \mathrm{~nm}$ and $254 \mathrm{~nm}$ is as shown in Figure 3.

\subsection{Melanogenesis Inhibition Activity}

Melanogenesis has been defined as the entire process leading to the formation of dark macromolecular pigments, which is melanin formed by a combination of enzymaticcally catalyzed and chemical reactions [21]. Studies have focused on the inhibition and prevention of abnormal pigmentation [22]. We found that the crude ethanolic and SFE extracts did not exhibit significant melanin inhibition activity, and the extracts were shown to be toxic to the melanocyte cells. Alpinia conchigera, crude aqueous extracts displayed a higher melanin inhibition of $96.38 \pm 1.60 \%$ and viability $109.90 \pm 8.32 \%$ at a concentration of $500 \mu \mathrm{g} / \mathrm{mL}$ in comparison with pure kojic acid at $100 \mu \mathrm{g} / \mathrm{mL}$. Thus, the crude aquous extract was further fractionated and purified to identify the active compounds that contributed to the anti-melanogenesis activity.

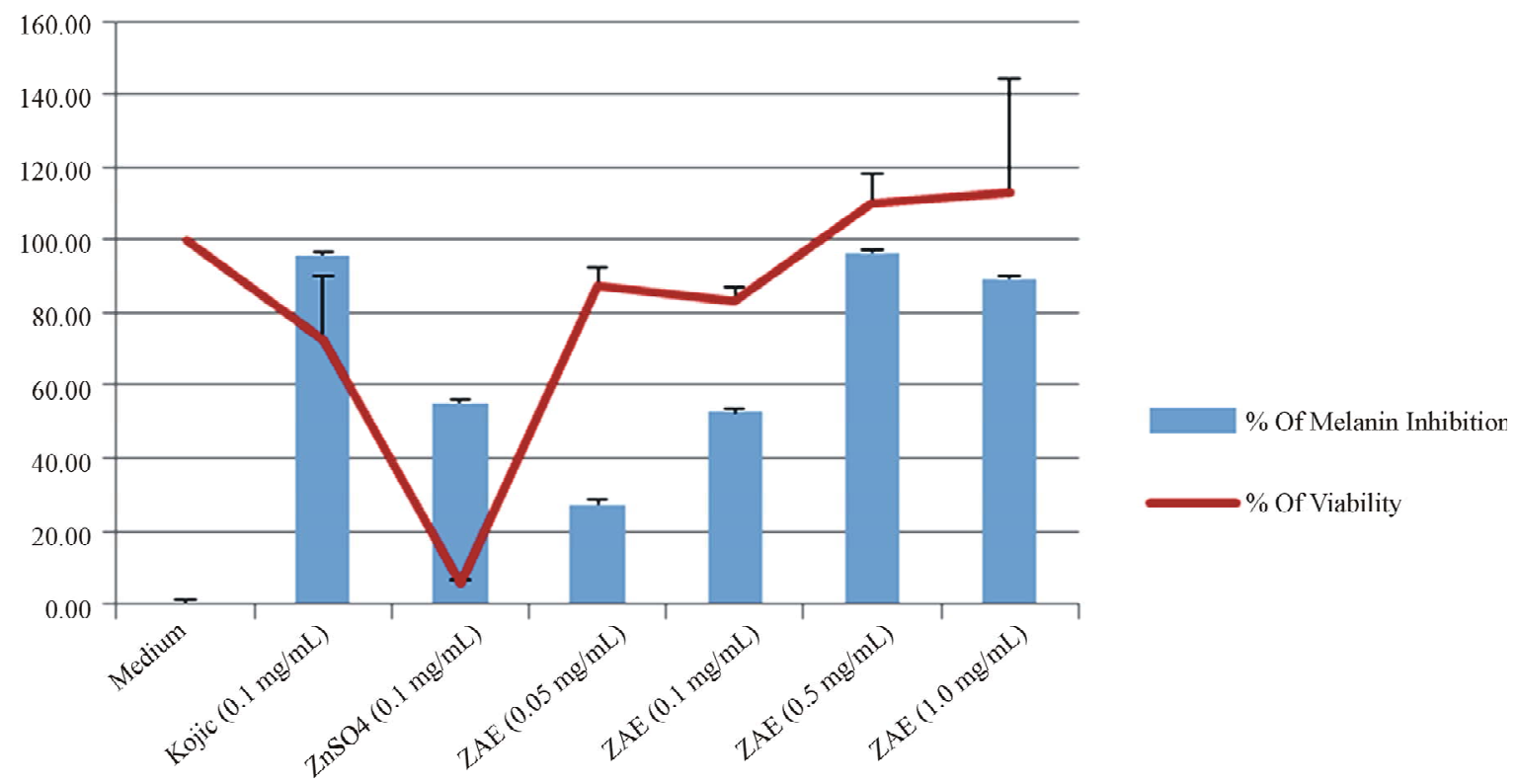

Figure 1. Crude Alpinia conchigera (ZAE) aqueous extract with dose dependant activity.

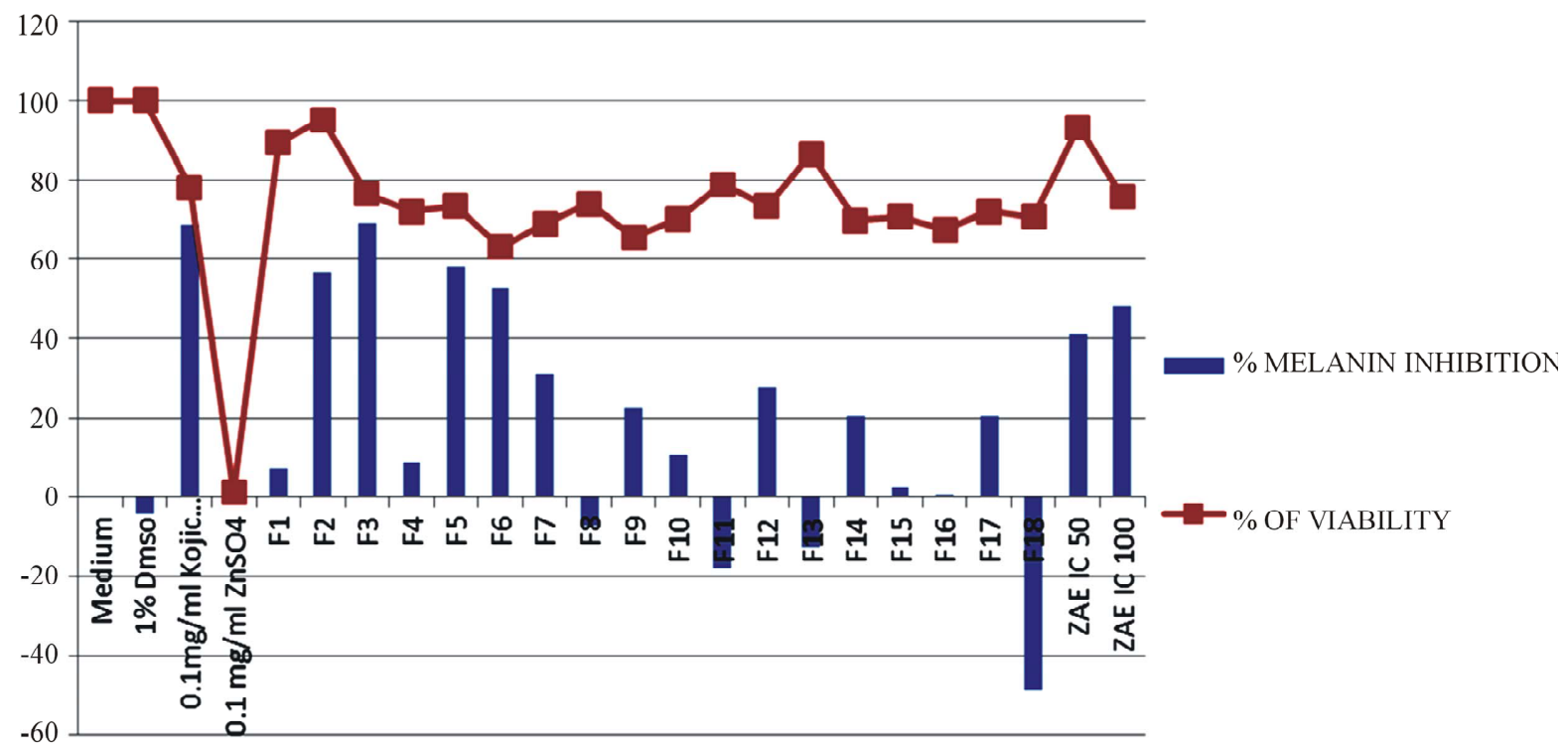

Figure 2. Melanogenesis inhibition activity and cell viability for Alpinia conchigera (ZAE) water extract and its fractions. 


\section{Fractionation and Isolation of the Active Compounds (Prep HPLC)}

The crude extract $(150 \mathrm{mg})$ was dissolved in methanol: water (50:50) and subjected to reversed phase C18 preparative HPLC. From the preparative chromatographic separation, 18 prominent fractions were collected in test tubes, dried and labeled as Fractions A - P. The fractions weights were calculated and diluted to two concentrations of $4.9 \mathrm{ug} / \mathrm{mL}$ and $14.8 \mathrm{ug} / \mathrm{mL}$ only as there were limitation to the amount of fractions collected for analysis. All the 18 fractions were subjected to melanogenesis inhibition and cell viability assay.

Fractions B and D showed good melanogensis inhibitory activity and cell viability (Figure 4). Both fractions were then analysed using HPLC and both were found to be quite pure compounds (Figures $\mathbf{5}$ and $\mathbf{6}$ ). The weight (mg) and yield (\%) of both the compounds derived from the aqueous extract were $(1.8 \mathrm{mg}, 8.7 \%)$ and $(5.8 \mathrm{mg}$, $27.9 \%$ ) respectively from a total extract weight of 20.8 mg from 150 mg crude extract.

Gilson Preparative HPLC C18: Water Novapak Column; Condition: gradient of $100 \%$ water $(0.1 \%$ formic acid) to $100 \%$ Acetonitrile ( $0.1 \%$ formic acid) over a duration of 50 mins, with a flow rate of $12 \mathrm{~mL} / \mathrm{min}$.

The bioactive compounds were then identified and characterized using LCMS and NMR methods and confirmed as Fraction B; chavicol glucopyranoside and Fraction D ; trans-cinnamaldehyde. The compounds exhibited 85\% melanogenesis inhibition at a low concentration of $4.9 \mu \mathrm{g} / \mathrm{mL}$ as shown in Figure 7, in comparison to kojic acid, a pure compound used commercially for skin lightening application. Zinc sulphate was chosen as a positive
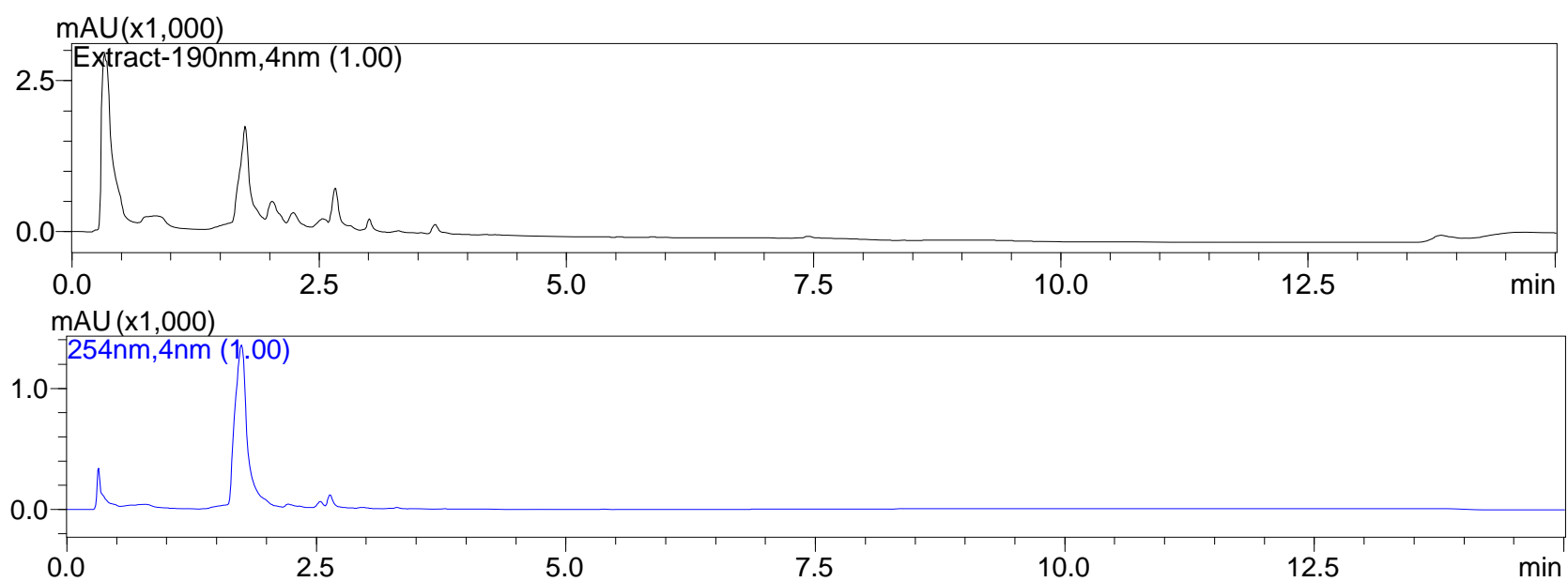

Figure 3. LCMS Chromatogram of Alpinia conchigera aqueous crude extract. Column: Waters X-Bridge, Condition: gradient of ACN (0.1\% formic acid) from 10\% to $100 \%$ at $0.1-7$ min at wavelength $190 \mathrm{~nm}$ and $254 \mathrm{~nm}$.

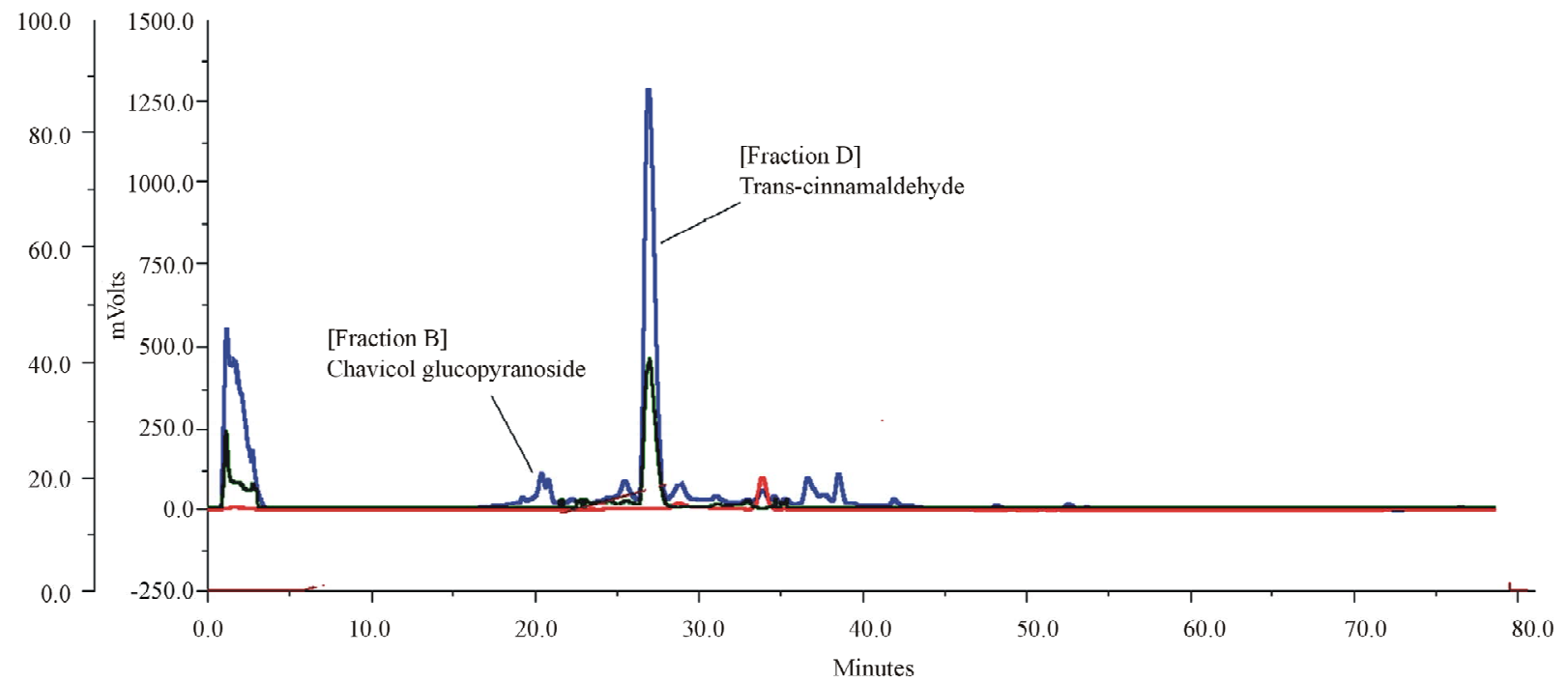

Figure 4. Preparative HPLC Chromatogram of Alpinia conchigera aqueous extract. 


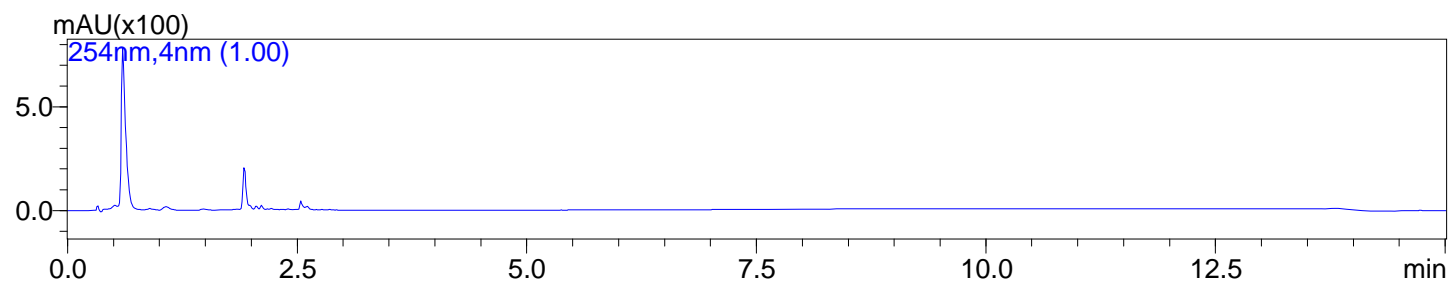

Figure 5. HPLC Chromatogram of chavicol glucopyranoside at wavelength $254 \mathbf{n m}$.

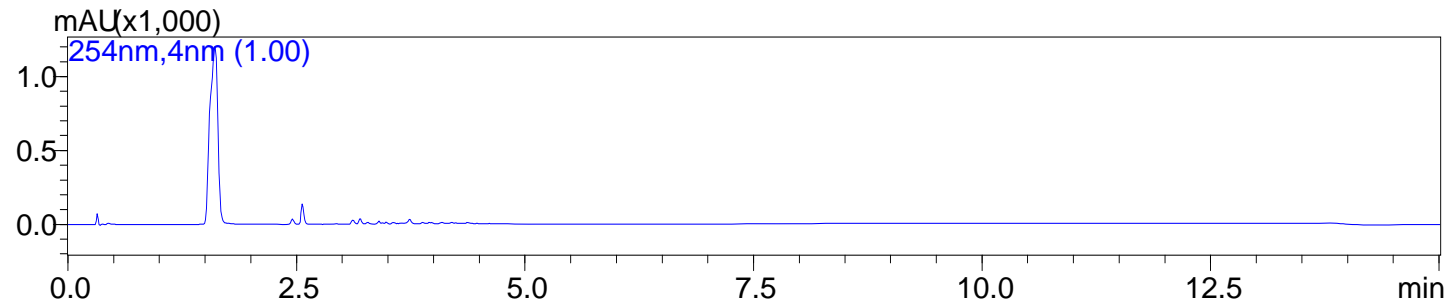

Figure 6. HPLC Chromatogram of trans cinnamaldehyde at wavelength $254 \mathbf{~ n m}$.

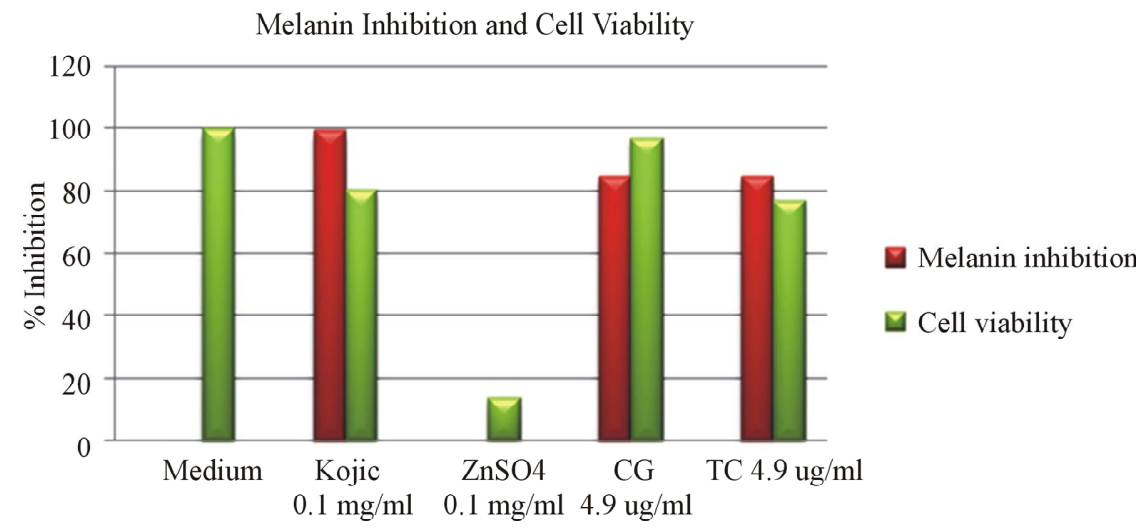

Figure 7. Melanogenesis inhibition activity and cell viability for Chavicol-glucopyranoside (CG) and Trans-cinnamaldehyde (TC) at $4.9 \mathrm{ug} / \mathrm{mL}$.

control for cell toxicity effect.

The chemical structures of the compounds are as shown in Figures 8 and 9 respectively; determined on the basis of MS and NMR data and the spectroscopic data in comparison with the reported literature [23]. It was noted that chavicol glucopyranoside(CG) is a very polar and non-toxic compound whereas trans-cinnamaldehye (TC) exhibited a dose dependent toxicity effect. The compound chavicol glucopyranoside has not been reported previously for anti-melanogenesis activity. Previous work has reported trans-cinnamaldehyde as having antityrosinase activity [24].

\section{Conclusion}

Previous study and extraction methods using different solvents and chromatographic conditions have been conducted to isolate active compounds from Curcuma mangga rhizomes on anti-tyrosinase inhibition property [25]. In this work, we have used a strategic approach to na-

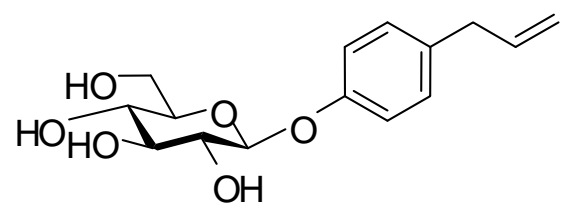

Figure 8. Chemical structure of chavicol-glucopyranoside.<smiles>O=C/C=C/c1ccccc1</smiles>

Figure 9. Chemical structure of transcinnamaldehyde.

tural product discovery and isolation process through direct use of techniques in the laboratory such as LCMS, and preparative HPLC to shorten its duration and enable a simplified process of fractionation, isolation and purification. From these applications, active fractions with high anti-melanogenesis activity from water extracts of Alp- 
inia conchigera were identified. The two compounds isolated from the active fractions were chavicol glucopyranoside and trans cinnamaldehyde. Due to its natural origin and, non-toxic effect, Alpinia conchigera water extract and its bioactive constituents have good potential to be used as a cosmetics active ingredient for skin lightening and depigmentation application.

\section{Acknowledgements}

The authors wish to acknowledge research funding from Ministry of Science, Technology and Innovation, Malaysia (MOSTI). We are also very grateful and thankful to Mr Lim Chuan Gee from IBRC SIRIM for his support in data and graph analysis.

\section{REFERENCES}

[1] A. M. Janssen and J. J. C. Scheffer, "Acetoxychavicol Acetate, an Antifungal Component of Alpinia Galanga,” Planta Medicine, Vol. 51, No. 6, 1985, pp. 507-511. doi:10.1055/s-2007-969577

[2] I. H. Burkill, "A Dictionary of the Economic Products in the Malay Peninsular, Ministry of Agriculture and Cooperatives,” 2nd Edition, Kuala Lumpur, 1966.

[3] H. Matsuda, S. Ando, T. Morikawa, S. Kataoka and M. Yoshikawa, "Structure-Activity Relationships of 1'S-1'-Acetoxychavicol Acetate for Inhibitory Effect on No Production in Lipopolisaccharide-Activated Mouse Peritoneal Macrophages," Bioorganic \& Medicinal Chemistry Letters, Vol. 15, No. 7, 2005, pp. 1949-1953.

doi:10.1016/j.bmcl.2005.01.070

[4] C. T. Campbell, M. Prince, G. M. Landry, V. Kha and H. E. Kleiner, "Pro-Apoptotic Effects of 1'-Acetoxychavicol Acetate on in Human Breast Carcinoma Cells," Toxicology Letters, Vol. 173, No. 3, 2007, pp. 151-160. doi:10.1016/j.toxlet.2007.07.008

[5] H. Ichikawa, Y. Takada, A. Murakami and B. B. Aggarwal, "Identification of a Novel Blocker of IkB[alpha] Kinase That Enhances Cellular Apoptosis and Inhibits Cellular Invasion through Suppression of NF-[kappa]B Regulated Gene Products," Journal of Immunology, Vol. 174, No. 11, 2005, pp. 7383-7392.

[6] A. Kondo, H. Ohigashi and A. Murakami, "A Potent Inhibitor of Tumor-Promoter-Induced Epstein Barr Virus Activation. 1'-Acetoxychavicol Acetate from Languas Galanga, a Traditional Thai Condiment," Bioscience, Biotechnology, and Biochemistry, Vol. 57, No. 8, 1993, pp. 13441345. doi:10.1271/bbb.57.1344

[7] V. J. Hearing, "Biogenesis of Pigment Granules: A Sensitive Way to Regulate Melanocyte Function,” Journal of Dermatological Science, Vol. 37, No. 1, 2005, pp. 3-14. doi:10.1016/j.jdermsci.2004.08.014

[8] S. Briganti, E. Camera and M. Picardo, "Chemical and Instrumental Approaches to Treat Hyperpigmentation,” Pigment Cell Research, Vol. 16, No. 2, 2003, pp. 101-110. doi:10.1034/j.1600-0749.2003.00029.x
[9] E. I. Solomon, U. M. Sundaram and T. E. Machonkin, "Multicopper Oxidases and Oxygenases,” Chemical Reviews, Vol. 96, No. 7, 1996, pp. 2563-2606. doi:10.1021/cr9500460

[10] M. Sieberg, J. Marthinuss and K. Stenn, "Changes in Expression of Apoptosis-Associated Genes in Skin Mark Early Catagen,” Journal of Investigative Dermatology, Vol. 104, 1995, pp. 78-82. doi:10.1111/1523-1747.ep12613555

[11] E. C. Davis and V. D. Callender, "A Review of the Epidemiology, Clinical Features, and Treatment Options in Skin of Color," The Journal of Clinical and Aesthetic Dermatology, Vol. 3, No. 7, 2010, pp. 20-31.

[12] P. G. Engasser and H. I. Maiback, "Cosmetics and Dermatology: Bleaching Creams," Journal of the American Academy of Dermatology, Vol. 5, No. 2, 1981, pp. 143147. doi:10.1016/S0190-9622(81)70082-3

[13] G. H. Findlay, J. G. L. Morrison and I. W. Simson, "Exogenous Ochronosis and Pigmented Colloid Milium from Hydroquinone Bleaching Creams," British Journal of Dermatology, Vol. 93, No. 6, 1975, pp. 613-622. doi:10.1111/j.1365-2133.1975.tb05110.x

[14] V. C. Vo, "Dictionary of Vietnamese Medicinal Plants," Publishing House Medicine, Ho Chi Minh City, 1997.

[15] Y. Pongpiriyadacha, P. Nuansrithong, O. Chumbuajan, N. Sirintharawech and D. Chantip, "Gastroprotective Effects of the Extract from Alpinia conchigera Griff., in Rats and the Possible Mechanism,” 2008.

[16] H. M. Sirat and A. B. Nordin, "Chemical Composition of the Rhizome Oil of Alpinia Conchigera Griff from Malaysia,” Journal of Essential oil Research, Vol. 7, 1995, pp. 195-197.

[17] S. Athamaprasangsa, U. Buntrarungroj, P. Dampawan, N. Ongkavoranan, V. Rukachaisirikul, S. Sethijinda, M. Sornnarintra, P. Sriwub and W. C. Taylor, "A 1,7-Diarylheptanoid from Alpinia Conchigera,” Phytochemistry, Vol. 37, No. 3, 1994, pp. 871-873. doi:10.1016/S0031-9422(00)90374-1

[18] K. C. Wong, B. C. Lee, N. F. Lam and P. Ibrahim, "Essential Oils of the Rhizomes of Alpinia conchigera Griff. and Alpinia latilabris Ridl,” Flavour and Fragrance Journal, Vol. 20, No. 4, 2005, pp. 431-433. doi:10.1002/ffj.1458

[19] H. Anita, A. M. Mustafa and H. Ibrahim, "Studies on Essential Oils of Alpinia Conchigera Griff. from Malaysia,” Malaysian Journal of Science, Vol. 19, No. 1, 2000, pp. 1-5.

[20] J. H. Lee, H. S. Jung, P. M. Giang, X. Jin, S. Lee, P. T. Son, D. Lee, Y. S. Hong, K. Lee and J. J. Lee, "Blockade of Nuclear Factor-KappaB Signaling Pathway and Anti-Inflammatory Activity of Cardamomin, a Chalcone Analog from Alpinia Conchigera,” Journal of Pharmacology And Experimental Therapeutics, Vol. 316, No. 1, 2006, pp. 271278. doi:10.1124/jpet.105.092486

[21] T. S. Chang, “An Updated Review on Tyrosinase Inhibitors," International Journal of Molecular Science, Vol. 10, No. 6, 2009, pp. 2440-2475. doi:10.3390/ijms10062440

[22] T. S. Chang, “Two Potent Suicide Substrates of Mushroom 
Tyrosinase: 7,8,4'-Trihydroxyisoflavone and 5,7,8,4'-Tetrahydroxyisoflavone,” Journal of Agricultural and Food Chemistry, Vol. 55, No. 5, 2007, pp. 3010-3015. doi:10.1021/jf063095i

[23] M. A. B. Hj, M. Sukari, M. B. Rahmani, T. S. Wah, A. M. Ali and M. N. B. H. Lajis, "Fundamental Science Congress Accelerating Research Excellence,” 2009, pp. 321-322.

[24] S.-Y. Seo, V. K. Sharma and N. Sharma, "Mushroom Ty- rosinase: Recent Prospects,” Journal of Agricultural and Food Chemistry, Vol. 51, No. 10, 2003, pp. 2837-2853. doi:10.1021/jf020826f

[25] S. N. A. Malek, G. S. Lee, S. L. Hong, H. Yaacob, N. A. Wahan, J.-F. F. Wweber and S. A. A. Shah, "Phytochemical and Cytotoxic Investigations of Curcumamangga Rhizomes,” Molecules, Vol. 16, 2011, pp. 4539-4548. 